\title{
Extensive study on the efficiency of a water repellent treatment on historic natural stone, brick and mortar
}

\author{
Daphne Guilbert ${ }^{\mathrm{a}, \mathrm{b}}$, Tim De Kock ${ }^{\mathrm{c}}$, Veerle Cnudde ${ }^{\mathrm{a}, \mathrm{d}}$, Nathan Van Den Bossche ${ }^{\mathrm{b}}$ \\ ${ }^{a}$ PProGRess, Department of Geology, Ghent University, Krijgslaan 281 S8, 9000 Ghent, Belgium \\ ${ }^{b}$ Building Physics Group, Department of Engineering and Architecture, Ghent University, Sint-Pietersnieuwstraat 41, B4, 9000 Ghent, Belgium \\ ${ }^{c}$ Antwerp Cultural Heritage Sciences (ARCHES), University of Antwerp, Mutsaardstraat 31, 2000 Antwerp, Belgium \\ ${ }^{d}$ Environmental Hydrogeology group, Department of Earth Sciences, Utrecht University, Princetonlaan 8a, 3584 CB Utrecht, The Netherlands
}

\begin{abstract}
In order to reduce water-related weathering of porous building materials, facades are often treated with a water repellent product. The efficacy of this treatment is generally tested in laboratory conditions, but these tests do not allow to grasp or understand the overall impact of the treatment on the hygrothermal behavior of a wall assembly. Therefore, heat-air-moisture (HAM) simulations can help to determine the treatment performance. However, water repellent layers are currently not well defined in HAM simulation programs. For this, three historic materials were extensively tested to determine the characteristics of a water repellent layer. Results show that the velocity of water absorption, 24 hour water uptake, drying speed and the sorption isotherm are, as expected, lower for treated materials. These results can be used to define water repellent layers in HAM simulations more correctly, in order to model their effect more accurately.
\end{abstract}

Peer-review under the responsibility of the organizing committee of the ICMB21.

Keywords: Water repellent treatment; historic building materials; water retention; water transport

\section{Introduction}

Most European cities have a historic center with heritage buildings, which are often built with porous building materials such as natural stone, brick and mortar. Due to their exposure to outdoor conditions, these porous materials are susceptible to several kinds of weathering processes, often triggered by the presence of water. The reduction of water inside these materials would be beneficial for the material's preservation and thus of facades in general. A method to ensure this reduction in water is the application of a water repellent product. Nevertheless, the use of water repellents is controversial and its use should be supported by a profound study and with respect to the known boundary conditions that may induce risks.

A water repellent treatment of a facade consists of the application of a hydrophobic product, often a water or solvent based mix of silanes and siloxanes, resulting in the deposition of a nanometric water repellent layer on the pore walls of the outer few millimeters to centimeters of the material. The deposition in nanometric layers on the pore walls has as consequence that water transport is still possible through water vapour transmission, which means drying of the wall is still feasible.

Theoretically, after the water repellent treatment, absorption of water by the facade's material is non-existent. However, in practice, the efficacy of a treatment depends on many factors, such as the presence of large pores and cavities, cracks, fouling, material dampness and salts [1]. Consequently, not all treatments lead to the expected reduction of water and in some cases deterioration accelerates after treatment (e.g. [2]). Therefore, the use of a water repellent needs a thorough evaluation before application, which is time and cost consuming. The adoption of heat-air-moisture (HAM) simulations [3] to simulate the moisture distribution within materials and wall assemblies after a water repellent treatment enables a more thorough understanding of a number of the processes, performance and risks associated with these treatments. However, water repellent layers are currently not well defined in such simulation programs. Consequently, in this study, several treated historic materials are laboratory tested and results will be used in a later stage for correctly defining a water repellent layer in a HAM-simulation program.

\section{Material and methodology}

Table 1. Test series used to determine different parameters. For each test series 15 samples of each material are used.

\begin{tabular}{|c|c|c|}
\hline & Test series 1 & Test series 2 \\
\hline Sample sizes & Cylindrical: $5 \mathrm{~cm}$ diameter and $5 \mathrm{~cm}$ height & Cubic: $3 \times 3 \times 1 \mathrm{~cm}^{3}$ \\
\hline Tests + standard & $\begin{array}{ll}- & \text { Water absorption by capillarity (NBN EN 1925:1999) } \\
- & 24 \text { hour water uptake } \\
- & \text { Drying mechanics (NBN EN 16322:2013) }\end{array}$ & - $\quad$ Hygroscopic sorption properties (NBN EN 12571:2013) \\
\hline Water repellent treatment & $\begin{array}{ll}- & \text { Samples placed in setup to mimic wall circumstances } \\
\text { - } & \text { Treated twice by wet-on-wet spraying with a 30-minute } \\
\text { interval on one side of the material }\end{array}$ & $\begin{array}{l}\text { Complete treatment by capillary absorption of the } \\
\text { product. }\end{array}$ \\
\hline
\end{tabular}




\section{ICMB21}

A commercially available solvent based product with $10 \%$ oligomeric siloxanes was used for the water repellent treatment of natural stone and brick masonry. After treatment, samples were placed in a $20^{\circ} \mathrm{C}$ and $50 \%$ relative humidity environment and the evolution of the polymerization process of the product was monitored by frequently weighing the samples.

One natural building stone, one brick and one lime mortar were tested on their water retention and transport characteristics. Savonnières limestone (SL) was chosen as natural building stone as this stone is often used in historic Belgian buildings [4]. Savonnières limestone was excavated in the Meuse Department, France. As brick, 'Oranje Paepesteen' (OP), which is a historic Flemish brick, was selected. Finally, the lime mortar (LM) was composed of pure raw materials: $29 \%$ of NHL3.5 and $71 \%$ of $0 / 2 \mathrm{~mm}$ river sand. Water was added based on workability. Two test series were used to determine different parameters (Table 1 ).

\section{Results and discussion}

After application of the water repellent product, samples were placed in a $20^{\circ} \mathrm{C}$ and $50 \%$ relative humidity environment. The monitored weight change of the treated samples shows for all materials an initial strong reduction, which is the result of evaporation of the solvent. This is followed by a slower decrease in weight due to the polymerization of the active material in the water repellent product.

Water absorption through capillarity and 24 hour water uptake tests indicate a strongly reduced water absorption speed for all materials (Fig. 1A) Although it is expected that a water repellent treatment leads to minimal water absorption, a limited water uptake is still found. This absorption of water is probably due to the presence of cracks or big pores. The exact cause will be studied in a next step using X-ray radiography.

Drying curves (e.g. Fig. 1B) show a slightly slower drying mechanism for the water repellent treated materials, which can be attributed to the repositioning of the drying front behind the water repellent layer. The drying curves indicate that water evaporation is reduced but is still possible through the water repellent layer by water vapour transmission.

Since the contact angle increases tremendously after treatment, one would expect that adsorption of water on pore walls is not occurring. However, Carmeliet et al. [5] found that also hydrophobic materials adsorb water on their pore walls. In accordance to their results, sorption isotherms in this study show water adsorption by both untreated and treated material, but with lower moisture contents for the treated material due to the higher contact angle (Fig. 1C).
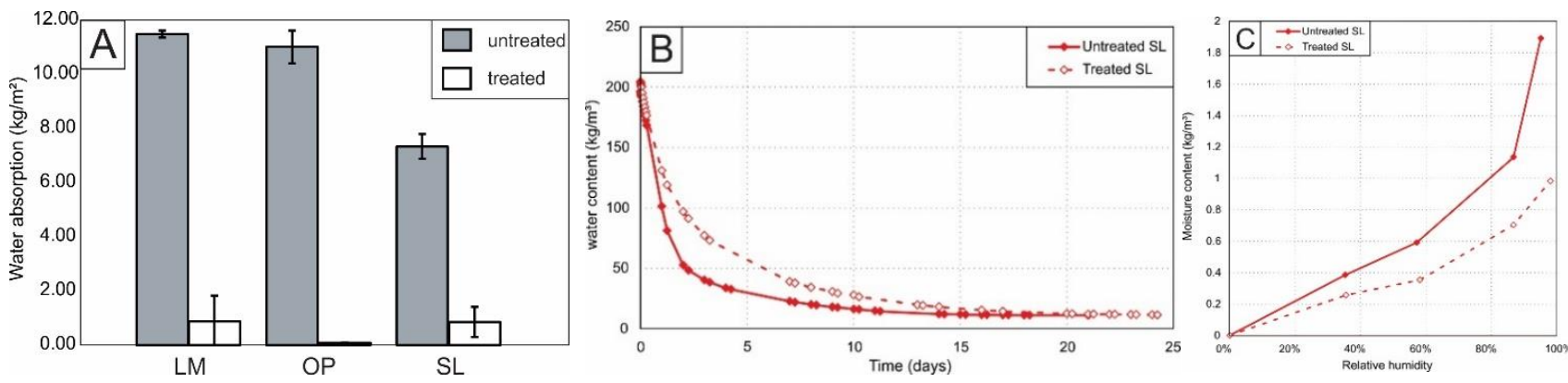

Figure 1: A: Water uptake after 24 hours absorption for untreated and treated materials. B: Drying behaviour of untreated and treated Savonnières limestone. C: Sorption isotherm of untreated and treated Savonnières limestone.

\section{Conclusion}

In this study, three porous historic building materials were treated with a water repellent and laboratory tested in order to characterize the water retention and water transport characteristics of these water repellent materials. As expected, water absorption speed and 24 hour water uptake of treated materials are significantly lower compared to untreated materials, but not equal to zero. The reason for this will be studied with X-ray radiography. Also, sorption isotherms are influenced by the application of a water repellent. The results of this study will be used to define water repellent layers in HAM-simulations at a later stage.

\section{References}

[1] WTCB, “TV 224: Waterwerende oppervlaktebehandeling," 2002.

[2] B. Lubelli, R. P. J. van Hees, C. Groot, and J. Gunneweg, "Risks of the use of water repellents on salt contaminated masonry: the case of a windmill in the Netherlands," Restor. Build. Monum. an Int. J. = Bauinstandsetz. und Baudenkmalpfl. eine Int. Zeitschrift, vol. 13, no. 5, p. $319,2007$.

[3] J. Grunewald, P. Haupl, and M. Bomberg, "Towards an Engineering Model of Material Characteristics for Input to Ham Transport Simulations Towards An Engineering Model of Material Characteristics for Input to Ham Transport Simulations - Part 1 : An Approach," J. Build. Phys., vol. 26, pp. 343-366, 2003.

[4] T. De Kock, J. Dewanckele, M. Boone, G. De Schutter, P. Jacobs, and V. Cnudde, "Replacement stones for Lede stone in Belgian historical monuments," in Stone in Historic Buldings: Characterisation and Performance, , 2014, pp. 31-46.

[5] J. Carmeliet, "Water Transport — Liquid and Vapour — in Porous Materials : Understanding Physical Mechanisms and Effects from Hydrophobic Treatments," in Hydrophobe III - 3rd International Conference on Surface Technology with Water Repellent Agents, 2001, pp. 171-178. 